\title{
Development of a questionnaire for the assessment of bronchial hyperresponsiveness
}

\section{*Roland Riemersma ${ }^{a}$, Dirkje Postma ${ }^{b}$, Huib Kerstjens ${ }^{b}$, Kevin Buijssen ${ }^{a}$, Marike Boezenc, Renee Aalbers ${ }^{\mathrm{d}}$, Wim Veldhuizen ${ }^{\mathrm{e}}$, Jaap Strijbos' ${ }^{\mathrm{f}}$, Thys van der Molen ${ }^{\mathrm{a}}$}

a Department of General Practice, University Medical Center Groningen, Groningen, Netherlands

b Department of Pulmonary Diseases, University Medical Center Groningen, Groningen, Netherlands

c Faculty of Medical Sciences, University Medical Center Groningen, Groningen, Netherlands

d Department of Pulmonary Diseases, Martini Hospital, Groningen, Netherlands

e Department of Pulmonary Diseases, Diaconessen Hospital, Meppel, Netherlands

${ }^{\ddagger}$ Department of Pulmonary Diseases, Nij Smellinghe Hospital, Drachten, Netherlands

Received 18th September 2008; revised 6th January 2009; accepted 31st January 2009; online 27th July 2009

\begin{abstract}
Introduction: Bronchial hyperresponsiveness (BHR) is a hallmark of asthma. Treatment approaches based on BHR severity have been shown to be effective. However, challenge tests are expensive, inconvenient to patients, time consuming, and not easily accessible to general practitioners. Assessment of BHR by a questionnaire would be advantageous in the diagnosis and management of asthma.

Aim: To select a set of respiratory symptoms and provoking stimuli related to BHR to compose a reliable Bronchial Hyperresponsiveness Questionnaire (BHQ).

Method: A list of 33 symptoms and 68 stimuli were selected by in-depth interviews, focus group discussions with asthma patients, and literature review. After a histamine challenge test patients $(n=302)$ were asked to score each question on a 7-point scale $(0=n o ; 6=s e v e r e$ complaints). Factor analysis was performed to identify clusters of interrelated symptoms associated with $\mathrm{PC}_{20}$-histamine. The sensitivity to detect the presence of BHR was analysed by Receiver Operating Curves (ROC). The correlation between the $\mathrm{PC}_{20}-\mathrm{Score}$ and the scores on the questions was analysed.

Results: 15 symptoms and 19 provoking stimuli were ultimately selected for the BHQ.

Conclusion: The BHQ was developed according to FDA-approved standards and is a condition-specific questionnaire able to assess the presence of $\mathrm{BHR}$.

(C) 2009 General Practice Airways Group. All rights reserved.

RA Riemersma et al. Prim Care Resp J 2009; 18(4): 287-293

doi:10.4104/pcrj.2009.00026
\end{abstract}

Keywords asthma, management, primary care, questionnaire, bronchial hyperresponsiveness

\section{Introduction}

Asthma is a chronic inflammatory disorder of the airways in which many cells and cellular elements play a role. This chronic inflammation is associated with airway hyperresponsiveness and leads to recurrent episodes of wheezing, breathlessness, chest tightness, and coughing, particularly at night or in the early morning. These episodes are usually associated with airway obstruction that is often reversible either spontaneously or with treatment. ${ }^{1}$
The chronic inflammatory process of the airways in asthma can lead to structural changes in the bronchial wall, a process known as airway remodelling which may be accompanied by lung function loss. ${ }^{2}$ Therefore, successful asthma management depends on effective suppression of inflammation and remodelling, generally by using inhaled corticosteroids (ICS)., ${ }^{3,4}$ In daily clinical practice, asthma treatment decisions are usually based on patient-reported symptoms and simple measures of lung function. Since

\footnotetext{
* Corresponding author: Mr RA Riemersma, Department of General Practice, University Medical Center Groningen, P.O. Box 196, Groningen, 9700 AD, Netherlands. Tel: +31596 622183 Fax: +31 596683455 E-mail: ra.riemersma@home.nl
} 
airway inflammation is only to a small extent associated with respiratory symptoms and lung function, symptom-based titration of the dose of ICS can be unreliable. Indeed, several studies have shown that the management of asthma improves and results in less exacerbations and better quality of life (QOL) with the provision of additional information about the severity of airway inflammation., 5

The gold standard for determining the severity of airway inflammation is a bronchial biopsy. Alternative methods have been sought over the years since biopsies are invasive, expensive and are therefore very impractical to use for a large number of subjects. Currently accepted and less invasive alternatives are the measurement of the level of exhaled nitric oxide, the number and type of inflammatory cells in induced sputum, and the severity of bronchial hyperresponsiveness (BHR). The latter has been shown to be associated with airway inflammation in several studies..$^{7-9}$

Sont et al have shown that treatment adjustments aimed at reducing BHR lead to more effective control of symptoms, fewer exacerbations, and a reduction in airways remodelling. ${ }^{10}$ These results suggest that measuring BHR at regular intervals in clinical practice could benefit standard monitoring of patients with asthma. However, there are several drawbacks; challenge tests are expensive, time consuming, not very convenient to patients, and are often not directly accessible in primary care. If the presence of $B H R$ could be determined with a questionnaire this would thus be cheaper, less time consuming and more convenient for both patients and doctors. Such a questionnaire could be of value in the management of asthma in primary care,

Although several attempts have been made to develop such a questionnaire, so far investigators have never applied structured patient interviews and proper questionnaire development rules as propagated (for instance) by the U.S. Department of Health and Human Services Food and Drug Administration (FDA). ${ }^{11,12}$ Thus these questionnaires were not specifically designed for the assessment of BHR but rather were modifications from other questionnaires. We hypothesised that it is crucial to pay detailed attention to the method of item selection in order to create a successful, condition-specific questionnaire. This article describes the methods of item collection and selection that we used to develop a questionnaire for the assessment of BHR in patients with asthma.

\section{Methods}

\section{Item collection for the preliminary questionnaire}

An initial pool of items was generated by literature review, ${ }^{13-16}$ in-depth interviews, and a focus group discussion with asthma patients. The search programs PubMed and Medline were used for the literature review, and the search terms used were "bronchial", "airway", "hyperreactivity", "hyper- responsiveness", "questionnaire", "stimuli", "triggers" and "triggering". Patients participating in the in-depth interviews and focus group discussion were selected from general practice. All participants had mild to moderately severe asthma as diagnosed by their general practitioner (GP) in agreement with the Dutch asthma guidelines ${ }^{17}$ (that are similar to the GINA-guideline'). The focus group discussion and single interviews began with open-ended questions followed by a semi-structured interview. Patients were asked to discuss the stimuli that provoked a deterioration of their asthma and the kind of symptoms that were experienced when asthma was not stable as opposed to when it was stable. The main goal was to collect as many different stimuli and symptoms related to BHR in daily life as possible. All interviews and focus group discussions were recorded on tape and transcribed. All mentioned stimuli and symptoms were listed in a questionnaire. The stem question of the symptom part of the questionnaire was; 'Did you experience "symptom $X^{\prime \prime}$, during the past 3 months?', whereas the stem question of the stimuli part was; 'Did "stimulus $X$ ", bother you during the past 3 months?'

With these selected questions a pre-test was performed. Six asthma patients filled in the questionnaire in the presence of a researcher. They were asked to recapture the last three months in answering the questions and to identify and discuss unclear questions with the researcher. The main objective of this pre-test was to eliminate errors and clarify obscurities in the questions. The remaining questions were collected in a preliminary questionnaire.

\section{Statistical analyses}

Data analyses were performed using the SPSS version 12 . Two of the four participating lung function centres assessed hyperresponsiveness by the 2-minute tidal breathing method (resulting in a $\mathrm{PC}_{20}$ ), the other two by the dosimeter method ( $\mathrm{PD}_{20}$ ). Two groups of patients were identified: 1) a group with a $20 \%$ fall in $\mathrm{FEV}_{1}\left(\mathrm{PD}_{20}<2.4 \mathrm{mg} ; \mathrm{PC}_{20}<32 \mathrm{mg} / \mathrm{ml}\right)$ and 2) a group without a $20 \%$ fall in $\mathrm{FEV}_{1}$.

Receiver Operating Curves (ROC) were made with all items of the preliminary questionnaire to investigate the sensitivity and specificity of each individual question to determine the presence or absence of BHR.

Factor analysis with no restriction on the number of factors was performed on all questionnaires completed by patients with BHR to identify clusters of interrelated questionnaire items. It was only performed on the symptom part of the preliminary questionnaire because questions pertaining to stimuli not encountered in the past three months could not be answered - thus these data could not be included for this type of analysis.

Spearman rank correlation tests were performed to investigate the relation between the level of $\mathrm{PC}_{20}$-histamine 
and the scores of each individual item in patients with doctordiagnosed asthma (see Figure 1). For this analysis, we only used individuals who underwent $\mathrm{BHR}$ testing with the $\mathrm{PC}_{20}$ histamine method, since this was used in the vast majority and moreover, conversion of $\mathrm{PC}_{20}$ into $\mathrm{PD}_{20}$ is difficult and not $100 \%$ reliable. ${ }^{18,19}$ Patients subjected to the $P_{20}$ measurement did not differ from those patients who were subjected to the $\mathrm{PC}_{20}$ measurements.

\section{Item generation}

The preliminary questionnaire consisted of questions about stimuli and symptoms. These questions were scored on a 7point Likert scale: $0=$ no complaints, $6=$ severe complaints. Questions about stimuli had " $X$ " as an extra answering option which implied: 'I have not been in contact with this stimulus during the past 3 months'. All patients who underwent a histamine challenge test were asked to complete the preliminary questionnaire directly after they had completed the challenge test. In this way the outcome of the challenge test (in this study used as the reference and gold standard for BHR) could be linked to the scores on the items of the preliminary questionnaire.

The investigator assigned each patient into one of the following diagnostic categories: 1. asthma; 2. COPD; 3. mixed asthma/COPD; 4. other diagnosis; and 5. not obtained (Figure 1). This allocation was based on the doctor's diagnosis, lung function scores and histamine scores collected from discharge letters and conforming to the Dutch asthma and COPD guidelines.
Cut-off values for the items to be included in the BHQ were a rho $\geq 0.2$ with a significance level $<0.05$ (Spearman rank correlation test) and/or an area under the curve $\geq 0.5$ with a significance level $<0.05$ (ROC). These cut-off values were determined by an expert panel consisting of a GP, a pulmonologist and a statistician.

\section{Results}

Item collection for the preliminary questionnaire

Eleven in-depth interviews and one focus group discussion were performed. After the pre-test procedure, 101 items remained for the preliminary questionnaire - 33 questions about symptoms and 68 about stimuli. This preliminary questionnaire was completed by 302 patients after BHR testing. Patient characteristics are presented in Table 1. Centres 1 and 2 ( $n=265)$ obtained $P C_{20}$ by the 2-minute tidal breathing method, centres 3 and $4(n=37) P_{20}$ by the dosimeter method. Asthma was diagnosed in 172, COPD in 7, mixed asthma/COPD in 11, and other diagnoses in 85 cases. The last category consisted of patients who were referred to the lung function centre for additional diagnostic tests by dermatologists, ear nose and throat-specialists, or allergologists. In 28 cases no diagnosis could be obtained because no discharge letter was available. $A P_{20}<2.4 \mathrm{mg}$ or a $\mathrm{PC}_{20}<32 \mathrm{mg} / \mathrm{ml}$ was obtained in 225 of the 302 patients.

\section{Clustering of items in the preliminary questionnaire}

Factor analysis on the scores of questionnaires from patients with BHR ( $n=225)$ showed eight clusters of symptoms. Five

Figure 1. Flowchart.

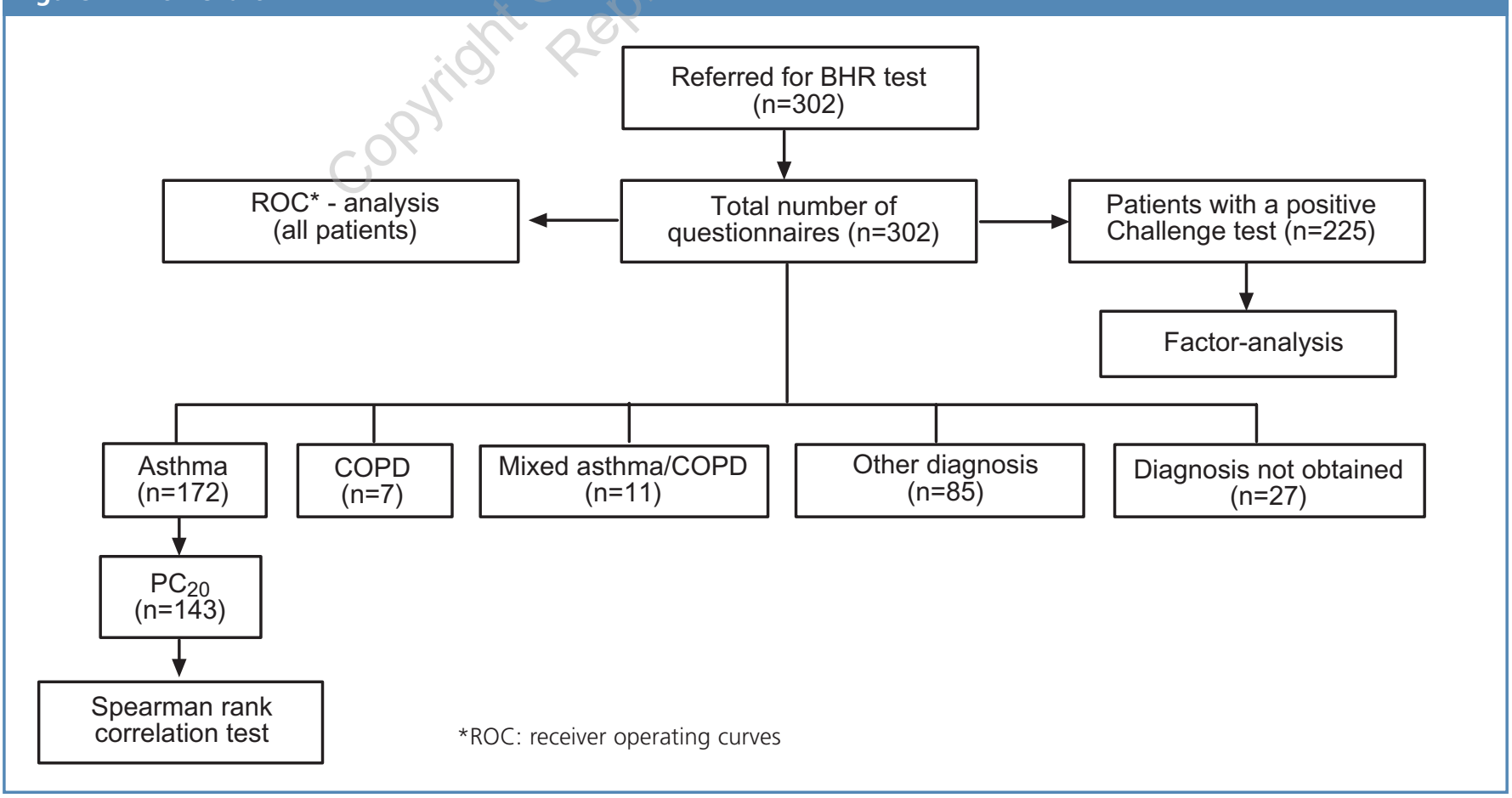


RA Riemersma et al.

\begin{tabular}{|c|c|c|c|}
\hline & $\mathrm{n}$ & $\%$ & \\
\hline $\begin{array}{l}\text { Hospital } \\
1 \\
2 \\
3 \\
4\end{array}$ & $\begin{array}{l}230 \\
35 \\
24 \\
13 \\
302\end{array}$ & $\begin{array}{l}76.2 \\
11.6 \\
7.9 \\
4.3 \\
100\end{array}$ & \\
\hline $\begin{array}{l}\text { Sex } \\
\text { male } \\
\text { female }\end{array}$ & $\begin{array}{l}115 \\
187\end{array}$ & $\begin{array}{l}38.1 \\
61.9\end{array}$ & $\begin{array}{c}\text { mean age (yrs) } \\
43.6 \\
37.2\end{array}$ \\
\hline $\begin{array}{l}\text { Smoking } \\
\text { yes } \\
\text { no } \\
\text { missing }\end{array}$ & $\begin{array}{l}59 \\
213 \\
30\end{array}$ & $\begin{array}{l}19.5 \\
70.5 \\
10\end{array}$ & \\
\hline $\begin{array}{l}\text { Hyperresponsiveness } \\
\text { yes } \\
\text { no }\end{array}$ & $\begin{array}{l}225 \\
77\end{array}$ & $\begin{array}{l}74.5 \\
25.5\end{array}$ & \\
\hline $\begin{array}{l}\text { Diagnosis } \\
\text { asthma } \\
\text { COPD } \\
\text { mixed asthma/COPD } \\
\text { other diagnosis } \\
\text { diagnosis not obtained }\end{array}$ & $\begin{array}{l}172 \\
7 \\
11 \\
85 \\
27\end{array}$ & $\begin{array}{l}57.0 \\
2.3 \\
3.6 \\
28.2 \\
8.9\end{array}$ & \\
\hline
\end{tabular}

clusters were quite homogeneous, and were associated with the following domains: difficulty in breathing (e.g. asthmalike symptoms), allergic symptoms, fever/chest pain, COPD-

like symptoms, and systemic complaints/malaise. The other clusters were more difficult to identify specifically (Table 2).

\section{Sensitivity of each item to predict BHR}

Sensitivity to predict BHR was determined using Receiver Operating Curves (ROC). Analysis was performed on all 101 items of the preliminary questionnaire in the total group of patients $(n=302)$. Each item was tested for its property to detect the presence of BHR. An item with an area under the curve of more than 0.5 is a potential indicator for the presence of BHR. The results of the ROC analysis are presented in Table 3.

\section{Correlation of each item with $\mathrm{PC}_{20}$-histamine score}

A Spearman rank correlation test was conducted on the items of the preliminary questionnaires completed by the group of patients in centres 1 and 2 with doctor-diagnosed asthma $(n=143)$. The investigated group consisted of 50 males, mean age 39.1 years and 99 females, mean age 34.4 years. Four patients had a $P C_{20}$-histamine of $\geq 32 \mathrm{mg} / \mathrm{ml}$, one of them used salmeterol $<12$ hours before the provocation test and was therefore left out of the analysis. The other three performed a correct challenge test and stayed in the analysis. Breathlessness, waking up at night due to chest tightness, shortness of breath, sensation of pressure on the chest, acute breathlessness, wheeze, panting/gasping, palpitation/fast heart rate and hyperventilation/fast breathing were significantly associated with the level of PC $_{20}$ (see Table 3).

Table 2. Results factor analysis of the symptoms.

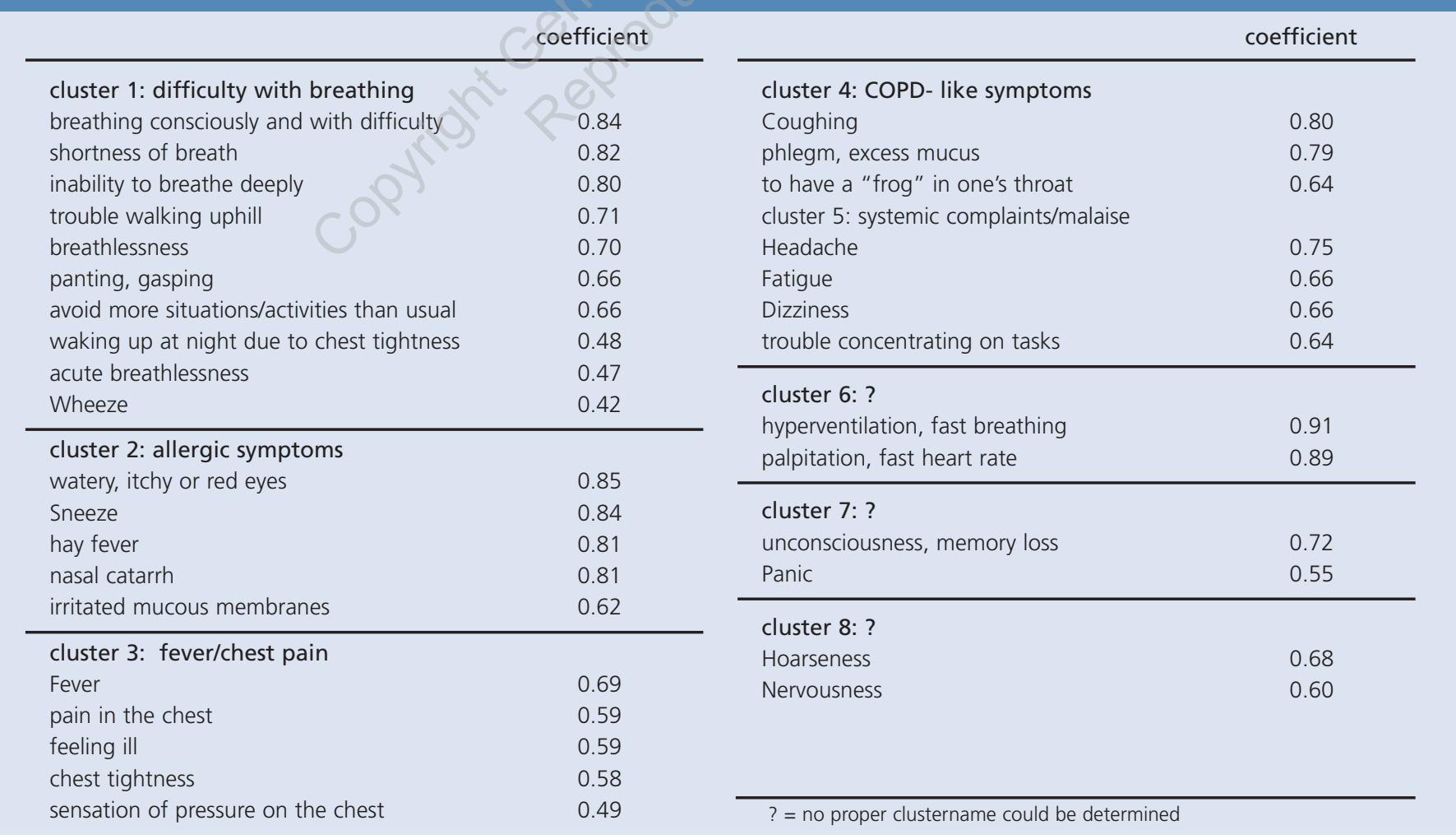




\section{Table 3. Results of ROC analysis and Spearman rank correlation test.}

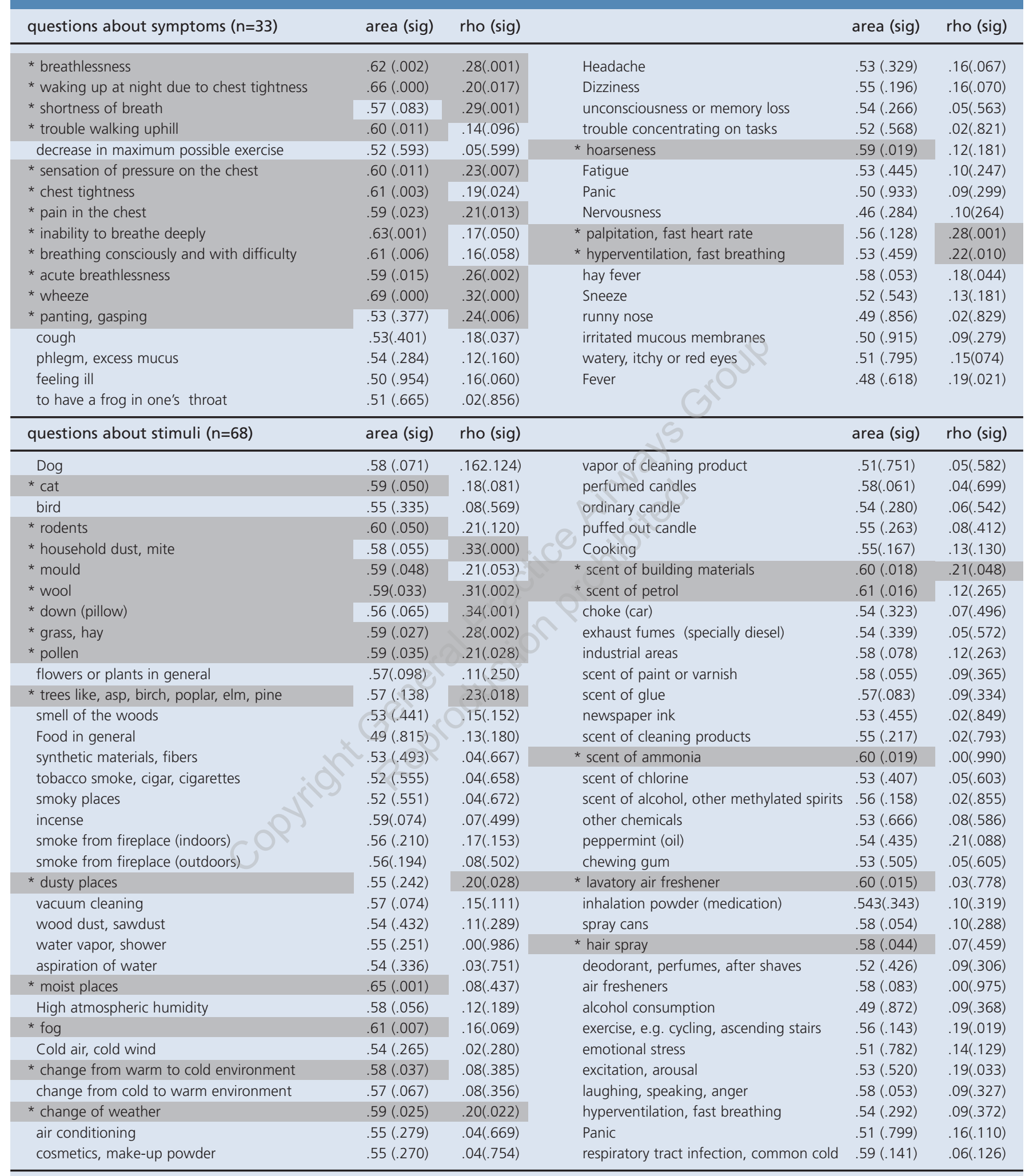

Explanation of Table 3:

Rho $=$ Spearman rho; area $=$ area under the curve of the ROC analysis; sig $=$ significance

Values with an area under the curve $\geq 0.5$ and a significance level $\leq 0.05$ are printed bold

Values with a rho $\geq 0.2$ and a significance level $\leq 0.05$ are printed bold

* grey and printed bold = questions selected for the $\mathrm{BHQ}$ 
Stimuli with significant associations with the level of $\mathrm{PC}_{20}$ were: household dust/mite; wool; down (pillow); grass/hay; pollen; trees like aspen/birch/poplar/elm/pine; dusty places; a change of weather; and the scent of building materials.

\section{Item generation for the BHR questionnaire}

Table 3 shows the results of the Spearman rank correlation test and the ROC analysis used to select items for the BHR Questionnaire (BHQ). The selection criteria for the correlation test were a rho $\geq 0.2$ and $p \leq 0.05$, and an area under the curve $\geq 0.5$ and $p \leq 0.05$ for the ROC analysis. Using these criteria, 34 items were selected for the BHQ, 15 from the symptom domain and 19 from the provoking stimulus domain.

\section{Discussion}

We developed a questionnaire in order to assess the presence and severity of BHR in asthma according to FDA-approved standards for the development of questionnaires. ${ }^{20}$ This BHR Questionnaire (BHQ) is a condition-specific questionnaire, consisting of 34 items - 15 regarding symptoms and 19 regarding provoking stimuli. As far as we are aware this is the first questionnaire specifically developed for the assessment of BHR in asthma. By using the $\mathrm{PC}_{20}$-histamine as the main reference we selected items for the $\mathrm{BHQ}$ thereby expecting the $\mathrm{BHQ}$ to be a condition-specific instrument.

Various attempts have been made in the past to find a relationship between symptoms and/or stimuli that provoke respiratory symptoms on the one hand, and the severity or presence of BHR on the other. Studies investigating this subject used questionnaires such as the International Union against Tuberculosis and Lung Disease (IUATLD) questionnaire, the Medical Research Council (MRC) questionnaire, the American Thoracic Society-Division of Lung Diseases (ATSDLD) questionnaire, or a subset of questions from these questionnaires. Although some questions derived from these questionnaires show a relation with BHR, so far no specific instrument has been developed to measure patient-perceived BHR.

Items related to BHR were generated by asthma patients. The expert panel decided to choose mild criteria for the item reduction. In this way they wished to prevent loss of possible predictive items. A disadvantage of this method is the relatively large number $(n=34)$ of questions selected for the BHQ. Completing the questionnaire takes about 10-15 minutes which may be too long to be suitable for use in daily clinical practice although it is less time consuming than a challenge test.

An interesting finding in this study is that even though the selection criteria were mild, some questions about stimuli that are intuitively related with BHR were not included in the BHQ. For example, questions about contact with smoke from fire places or tobacco smoke proved to have little relation with
PC 20 -histamine in our sample and were excluded. We can only speculate as to the reasons for this finding. It may well be that (tobacco) smoke is not specific enough to discriminate. This could mean that it is only a useful question in people not currently smoking.

Another remarkable finding is that hyperventilation as a symptom was selected for the BHQ whilst hyperventilation as a stimulus did not pass the selection criteria. Perhaps the way of asking the question explains the difference; as a symptom the question about hyperventilation was: "Did you experience hyperventilation / fast breathing during the last 3 months?" As a stimulus the question was: "Did hyperventilation / fast breathing bother you during the last 3 months?"

Symptoms like cough, phlegm, and excess mucus occur in asthma but are more often associated with COPD. Questions about these symptoms were not selected for the BHQ. This may have been due to the fact that the item generation was performed in predominantly asthmatic patients (Table 1). Of interest, allergic symptoms like nasal catarrh, watery, itchy or red eyes, hay fever and an irritated mucous membrane (Table 2, cluster 2) also showed little relation with $P C_{20}$-histamine and therefore were not included in the BHQ. This is remarkable because there is a close relation between allergic rhinitis and asthma. Epidemiological studies show that up to $60-78 \%$ of patients with asthma have coexisting allergic rhinitis, whereas $20-38 \%$ of patients with allergic rhinitis have asthma. ${ }^{21,22}$ Because the inflammatory processes involved in both diseases show large similarity some authors even speak of "one airway, one disease". ${ }^{23}$ For the selection of questions we mainly focused on respiratory symptoms which is one explanation for our finding. The second explanation is the use of $\mathrm{PC}_{20}$-histamine as the gold standard. This test is not exclusively sensitive to allergic triggers but also detects the BHR to non-allergic triggers.

In summary, we performed an active and systematic search for questions related to the presence and/or severity of BHR. By doing so according to FDA-proposed rules for the development of questionnaires, we created a conditionspecific questionnaire that adds information about the presence of BHR in patients with asthma. Further research is necessary to check the predictive value of the questionnaire against the gold standard $\mathrm{PC}_{20}$ to warrant its value and its accuracy in the management of asthma.

\section{Conflict of interest}

None.

\section{References}

1. Global Strategy for Asthma Management and Prevention NIH publication No 02-3659 Issued January, 1995, last update 2006. The GINA reports are available at URL http://www.ginasthma.org

2. Ward C, Pais M, Bish R, Reid D, Feltis B, Johns D, Walters EH. Airway inflammation, basement membrane thickening and bronchial 
hyperresponsiveness in asthma. Thorax 2002;57:309-16. http://dx.doi.org/ 10.1136/ thorax.57.4.309

3. Rees J. Asthma control in adults. BMJ 2006;332:767-71. http://dx.doi.org/ 10.1136/bmj.332. 7544.767

4. Ng D, Salvio F, Hicks G. Anti-leukotriene agents compared to inhaled corticosteroids in the management of recurrent and/or chronic asthma in adults and children. Cochrane Database Syst Rev 2004;(2):CD002314.

5. Green RH, Brightling CE, McKenna S, et al. Asthma exacerbations and sputum eosinophil counts: a randomised controlled trial. Lancet 2002;360:1715-21. http://dx.doi.org/10.1016/S0140-6736(02)11679-5

6. Sont JK, Willems LN, Bel EH, van Krieken JH, Vandenbroucke JP, Sterk PJ. Clinical control and histopathologic outcome of asthma when using airway hyperresponsiveness as an additional guide to long-term treatment. Am J Respir Crit Care Med 1999;159:1043-51.

7. Sont JK, Han J, van Krieken JM, et al. Relationship between the inflammatory infiltrate in bronchial biopsy specimens and clinical severity of asthma in patients treated with inhaled steroids. Thorax 1996;51:496-502. http:// dx.doi.org/10.1136/thx.51.5.496

8. Britton JR, Burney PG, Chinn S, Papacosta AO, Tattersfield AE. The relation between change in airway reactivity and change in respiratory symptoms and medication in a community study. Am Rev Respir Dis 1988;138:530-34.

9. van Den Toorn LM, Prins JB, Overbeek SE, Hoogsteden HC, de Jongste JC. Adolescents in clinical remission of atopic asthma have elevated exhaled nitric oxide levels and bronchial hyperresponsiveness. Am J Respir Crit Care Med 2000;162:953-7.

10. Sont JK. How do we monitor asthma control? Allergy 1999;54:68-71. http://dx.doi.org/10.1111/j.1398-9995.1999.tb04391.x

11. Venables KM, Farrer N, Sharp L, Graneek BJ, Newman Taylor AJ. Respiratory symptoms questionnaire for asthma epidemiology: validity and reproducibility. Thorax 1993;48:214-19. http://dx.doi.org/10.1136/thx.48.3.214

12. Burney PG, Chinn S, Britton JR, Tattersfield AE, Papacosta AO. What symptoms predict the bronchial response to histamine? Int J Epidemiol 1989;18:165-73.

13. Mortagy AK, Howell JB, Waters WE. Respiratory symptoms and bronchial reactivity: identification of a syndrome and its relation to asthma. BMJ 1986;293:525-9. http://dx.doi.org/10.1136/bmj.293.6546.525

14. Kolnaar BG, Janssen JL, Folgering $H$, van den Hoogen $H J$, van Weel $C$. The relationship between respiratory symptoms and bronchial hyperresponsiveness in a population-based sample of adolescents and young adults. Respir Med 1995;89:93-100. http://dx.doi.org/10.1016/0954-6111(95)90190-6

15. Woolcock AJ, Peat JK, Salome CM, et al. Prevalence of bronchial hyperresponsiveness and asthma in a rural adult population. Thorax 1987;42:361-8. http://dx.doi.org/10.1136/thx.42.5.361

16. Postma DS, Kerstjens HA. Characteristics of airway hyperresponsiveness in asthma and chronic obstructive pulmonary disease. Am J Respir Crit Care Med 1998;158:187-92.

17. Geijer RMM, Hensbergen van W, Bottema BJAM, et al. NHG-Standaard Astma bij Volwassenen: behandeling. Huisarts Wet 2001;44:153-64.

18. Ryan G, Dolovich MB, Roberts RS, et al. Standardisation of inhalation provocation tests: two techniques of aerosol generation and inhalation compared. Am Rev Resp Dis 1981;123:195-9.

19. Britton J, Mortagy A, Tattersfield A. Histamine challenge testing: comparison of three methods. Thorax 1986;41:128-32. http://dx.doi.org/10.1136/ thx.41.2.128

20. U.S. Department of Health and Human Services Food and Drug Administration et al. Guidance for Industry: Patient-reported outcome measures: use in medical product development to support labeling claims www.fda.gov/cder/ guidance/5460dft.htm

21. Bousquet J, Van Cauwenberge $P$, Khaltaev N. Allergic Rhinitis and its Impact on Asthma. J Allergy Clin Immunol 2001;108:147-334. http://dx.doi.org/ 10.1067/mai.2001.118891

22. Downie SR, Andersson M, Rimmer J, et al. Association between nasal and bronchial symtoms in subjects with persistent allergic rhinitis. Allergy 2004;59:320-6. http://dx.doi.org/10.1111/j.1398-9995.2003.00419.x

23. Grossman J. One airway, one disease. Chest 1997;111:11-16 http://dx.doi.org/10.1378/chest.111.2_Supplement.11S

\section{Available online at http://www.thepcrj.org}

